\title{
Instrumentos para la contratación pública estratégica: el ciclo de vida de los productos y servicios y su coste ${ }^{1}$
}

\author{
Manuel Jesús Rozados Oliva
}

Profesor Titular de Derecho Administrativo

Universidad de Cádiz

\begin{abstract}
SUMARIO: I. INTRODUCGIÓN. II. EL GICLO DE VIDA Y EL COSTE DEL CICLO DE VIDA DE LOS PRODUCTOS Y SERVICIOS EN LA CONTRATAGIÓN PÚBLICA: 1 . El concepto de ciclo de vida de un producto o servicio y su análisis. 2. El coste del ciclo de vida de un producto o servicio y su introducción en el régimen de la contratación pública. III. EL COSTE DEL CICLO DE VIDA DE LOS PRODUCTOS Y SERVICIOS COMO CRITERIO DE ADJUDICACIÓN EN LA CONTRATACIÓN PÚBLICA: 1. Los criterios de adjudicación en la LCSP: la sustitución de la "oferta económicamente más ventajosa" por la "mejor relación calidad-precio". 2. El cálculo del coste del ciclo de vida como criterio de adjudicación alternativo al precio. 3. Los requisitos y condiciones para la introducción del cálculo del coste del ciclo de vida como criterio de adjudicación. IV. REFLEXIÓN FINAL. V. BIBLIOGRAFÍA
\end{abstract}

RESUMEN: En la última reforma en el ámbito de la contratación pública se ha producido una evolución en el planteamiento de la utilización estratégica de la misma. Dentro de los nuevos esquemas que la legislación europea y española pretenden imponer, se incorporan dos instrumentos ya existentes en el ordenamiento jurídico, pero que cobran un nuevo protagonismo: el ciclo de vida y el coste del ciclo de vida de los productos o servicios. Tradicionalmente considerados como dos elementos propios de la incorporación de cláusulas ambientales en el marco de la contrata-

$1 \quad$ El presente trabajo ha sido realizado en el marco del proyecto de investigación "La sostenibilidad como idea rectora de las políticas públicas y de la prestación de servicios públicos para el bienestar de los ciudadanos" (DER2017-83864-R), del Ministerio de Economía y Competitividad.

Recibido: 30/07/2019

Aceptado: 20/09/2019 
ción pública, su virtualidad va más allá de su dimensión ambiental, constituyendo dos herramientas relevantes para el desarrollo de la contratación pública estratégica.

PALABRAS CLAVE: Contratación Pública Estratégica, ciclo de vida, coste del ciclo de vida

ABSTRACT: In the last reform in the field of public procurement there has been an evolution in the approach to its strategic use. Within the new schemes that European and Spanish legislation intends to impose, two existing instruments are incorporated in the legal system, but which take on a new role: the life cycle and the cost of the life cycle of the products or services. Traditionally considered as two elements of the incorporation of environmental clauses in the framework of public procurement, its virtuality goes beyond its environmental dimension, constituting two relevant tools for the development of strategic public procurement.

KEY WORDS: Strategic Public Procurement, life cycle, life cycle cost

\section{INTRODUGGIÓN.}

La importancia de la contratación pública en el desarrollo económico de un país es una afirmación tan notoria que no requiere de mayor precisión cuantitativa. Las cifras pueden oscilar en función de la fuente, pero todas coinciden en que supone una parte importante del PIB español y europeo ${ }^{2}$. La proyección de la contratación pública en el funcionamiento de la economía la convierte por tanto en protagonista relevante de su marcha. Desde esta perspectiva, es razonable que los planteamientos regulatorios en esta materia hayan evolucionado, como señala GIMENO FELIÚ, desde una visión principalmente presupuestaria, basada en la visión del contrato público como gasto, a su consideración como inversión ${ }^{3}$. Este cambio de enfoque conduce al tratamiento de la contratación pública como una herramienta de excepcional valor en el desarrollo de políticas públicas, nacionales y europeas, con una utilidad

2 En el caso de España, según un reciente informe de la Comisión Nacional de los Mercados y de la Competencia sobre Radiografia de los Procedimientos de Contratación Pública en España (E/CNMC/004/18), de 7 de febrero de 2019, la contratación pública representa entre el 10 y el 20\% del PIB español. En cuanto al ámbito europeo, son reiteradamente citadas las cifras que se contienen en Adquisiciones ecológicas. Manual sobre la contratación pública ecológica, editado por la Comisión Europea, $3^{\text {a }}$ edición, 2016, tomadas del documento Public Procurement Indicators 2013, también elaborado por la Comisión Europea, en el que se cifra la contratación pública en el conjunto europeo en un volumen de 1,8 billones de euros anuales, representando un 14\% del PIB de la UE (advirtiendo una comparativa descendente con las cifras arrojadas en 2011, que alcanzaban a 2,3 billones de euros y un 19\% del PIB europeo).

3 C frr. GIMENO FELIÚ, J.M., "La nueva regulación de la contratación pública en España desde la óptica de la incorporación de las exigencias europeas: hacia un modelo estratégico, eficiente y transparente", en GIMENO FELIÚ, J.M. (Dir.), Estudio sistemático de la Ley de Contratos del Sector Público, Thomson Reuters - Aranzadi, 2018, pág. 91. 
estratégica indudable como elemento dinamizador de un crecimiento sostenible, que gestione los recursos disponibles de forma más equilibrada y eficiente. Esta concepción como instrumento estratégico ha cobrado un especial relieve en el marco de las Directivas de 2014, y en consecuencia, en la nueva Ley 9/2017, de 8 de noviembre, de Contratos del Sector Público (LCSP) ${ }^{5}$, lo que ha motivado un creciente interés en su estudio desde esta perspectiva ${ }^{6}$. Siguiendo esta línea, la Exposición de Motivos de la LCSP expresa la finalidad de utilizar la contratación pública "como instrumento para implementar las politicas tanto europeas como nacionales en materia social, medioambiental, de innovación y desarrollo, de promoción de las PYMES, y de defensa de la competencia", planteando como objetivo conseguir con la nueva regulación una mejor relación calidad-precio en la adquisición y consumo de productos y servicios, fin este último para el que se introducen en los criterios de adjudicación aspectos cualitativos, medioambientales, sociales e innovadores vinculados al objeto del contrato.

De este modo, tres de los vectores sobre los que va a girar el desarrollo de la contratación pública estratégica se refieren, por tanto, a su dimensión social, medioambiental e innovadora. Para lograr los objetivos propuestos, en este contexto, se han aprobado recientemente el Plan de Contratación Pública Ecológica (PCPE), por acuerdo del Consejo de Ministros de 7 de diciembre de 2018 para el período 2018-2025 (Orden PGI/86/2019, de 31 de enero) ${ }^{7}$, y el Plan para el impulso de la contratación pública socialmente responsable (PCPSR), aprobado por el Consejo de Ministros de 12 de abril de 2019 (Orden PCI/566/2019, de 21 de mayo) ${ }^{8}$. Se trata de un avance más en la introducción de las cláusulas sociales y medioambientales en el ámbito de la contratación pública, ya arraigadas en el régimen normativo de la

4 En concreto, la Directiva 2014/23/UE, la Directiva 2014/24/UE y la Directiva 2014/25/ UE, todas ellas de 26 de febrero de 2014. Como expresa el considerando 2 de la Directiva 2014/24/UE, la contratación pública "desempeña un papel clave en la Estrategia Europa 2020, establecida en la Comunicación de la Comisión de 3 de marzo de 2010..., como uno de los instrumentos basados en el mercado que deben utilizarse para conseguir un crecimiento inteligente, sostenible e integrador, garantizando al mismo tiempo un uso más eficiente de los fondos públicos".

5 En cuya Exposición de Motivos se reproduce en su primer epígrafe, de modo literal, el contenido completo del considerando 2 de la Directiva 2014/24/UE citado en la nota anterior.

6 Sobre la contratación pública estratégica puede consultarse una abundante bibliografía, de entre la que podemos destacar algunos trabajos: vid., inter alia, FERNÁNDEZ ACEVEDO, R., "Los retos ambientales de las nuevas directivas. La contratación pública como estrategia”, en RAZQUIN LIZARRAGA, M.M. (Dir.), Nueva contratación pública: mercado y medio ambiente, Thomson Reuters - Aranzadi/ Universidad Pública de Navarra, 2017; GIMENO FELIÚ, J.M., "El nuevo paquete legislativo comunitario de contratación pública: principales novedades. La orientación estratégica de la contratación pública”, en RODRÍGUEZ-CAMPOS GONZÁLEZ, S. (Coord.), Las nuevas directivas de contratos públicos y su transposición, Marcial Pons, 2016, y El nuevo paquete legislativo comunitario sobre contratación pública. De la burocracia a la estrategia (El contrato público como herramienta de liderazgo institucional de los poderes públicos), Thomson Reuters - Aranzadi, 2014; PERNÁS GARGíA, J. (Dir.), Contratación Pública Estratégica, Thomson Reuters - Aranzadi, 2013.

Vid. BOE núm. 30, de 4 de febrero de 2019.

8 Vid. BOE núm. 125, de 25 de mayo de 2019. 
misma ${ }^{9}$, que tendrá su continuidad a buen seguro en el desarrollo de la contratación pública innovadora ${ }^{10}$.

Sobre estas bases, con la reciente reforma del régimen normativo en materia de contratación pública, fruto de la trasposición de las Directivas europeas, cobra un especial protagonismo la utilización de dos instrumentos que ya se encontraban presentes en nuestro ordenamiento jurídico, y que ahora deben incrementar su utilidad, más allá del papel hasta el momento secundario que han tenido en cada uno de los ámbitos en los que se han introducido: el ciclo de vida y el coste del ciclo de vida de los productos y servicios, este último como criterio de adjudicación de los contratos. En ambos casos, como veremos, se ha vinculado su aparición y su utilidad con la inclusión de cláusulas y criterios medioambientales en la regulación de la contratación pública. Sin embargo, sin denostar en absoluto la dimensión medioambiental de cada una de estas herramientas, es necesario abordar un análisis de su incorporación en el nuevo régimen para advertir su valor como instrumentos que facilitan la implementación de la visión estratégica de la contratación pública, más allá de servir como elementos que coadyuvan a la materialización de una compra pública más sostenible desde el plano ambiental.

\section{EL GICLO DE VIDA Y EL COSTE DEL GICLO DE VIDA DE LOS PRODUCTOS Y SERVICIOS EN LA CONTRATACIÓN PÚBLICA.}

\section{El concepto de ciclo de vida de un producto o servicio y su análisis.}

Uno de los elementos que caracterizan el desarrollo de las modernas políticas globales en materia de contratación pública, desde el prisma de la introducción de principios y reglas estratégicas, dirigidas a procurar la mayor eficiencia en la gestión del gasto público y a su vez la utilización del mismo como instrumento de crecimien-

9 Un completo estudio sobre la introducción de ambas podemos encontrarlo en el excelente trabajo de GÓMEZ RUIZ, M., Aspectos sociales y medioambientales en la contratación pública, Tesis Doctoral, Universidad de Cádiz, noviembre de 2015, accesible en el repositorio https://rodin.uca.es.

10 Sobre la innovación en el ámbito de la contratación pública se han ocupado numerosos trabajos recientes, entre ellos GARCÍA JIMÉNEZ, A., Las conexiones entre contratación pública e innovación, Tecnos, 2018; HERNANDO RYDINGS, M., "El procedimiento de asociación para la innovación”, en GIMENO FELIÚ, J.M., Estudio sistemático de la Ley de Contratos del Sector Público, Thomson Reuters - Aranzadi, 2018; NUÑEZ LOZANO, C., "La contratación pública innovadora", en HERNÁNDEZ GONZÁLEZ, F.L., El impacto de la crisis en la contratación pública: España, Italia, Francia, Thomson Reuters - Aranzadi, 2016; RODRÍGUEZ BEAS, M., "La compra pública innovadora en la nueva Directiva de Contratación Pública", y FERNÁNDEZ SCAGLIUSI, Ma A., "Un nuevo procedimiento de adjudicación de contratos públicos: la asociación para la innovación", ambos trabajos en GIMENO FELIÚ, J.M. (Dir.), Las nuevas Directivas de Contratación Pública, Thomson Reuters - Aranzadi, 2015. 
to sostenible, tiene relación con la introducción paulatina del concepto de ciclo de vida de los productos y servicios hasta llegar a la incorporación del cálculo de su coste como criterio de adjudicación de los contratos públicos.

El concepto de ciclo de vida de un producto o servicio se refiere, en una primera aproximación sencilla, a la consideración de todo el tiempo que transcurre desde antes de su propia existencia (su proyección, planteamiento, invención o, incluso, el desarrollo de la investigación necesaria para llegar a su concreción), hasta que finaliza su utilización y desaparece. Se trata de una noción de la ciencia económica, inicialmente asociada al ámbito del marketing, cuyo estudio sin embargo no comienza a tomar interés hasta que es analizado por LEVITT, quien destaca, en la década de los sesenta del siglo pasado, el nulo aprovechamiento estratégico de esta herramienta hasta ese momento ${ }^{11}$. A partir de entonces, el análisis de las fases de vida de un producto se convierte en un instrumento de extraordinario interés para el marketing, pues permite adoptar las decisiones más idóneas en función de la etapa en la que el producto se encuentra (desarrollo, crecimiento, madurez o declive), y por tanto definiendo las estrategias comerciales que mejor se ajusten al momento en el que el producto se desenvuelve en el mercado. Más allá del ámbito del marketing, con el tiempo el ciclo de vida de un producto se ha convertido también en un mecanismo de relevante utilidad en la contabilidad de gestión, mediante el cálculo del coste del mismo, introduciendo de este modo criterios de decisión estratégica derivados de la medición y el control de los costes de las empresas ${ }^{12}$. De estas notas introductorias sobre el origen y la funcionalidad de los conceptos de ciclo de vida del producto y de coste de dicho ciclo en el ámbito de la ciencia económica se extraen inicialmente dos aspectos que van a ser decisivos en su implementación en el régimen jurídico de la contratación pública: su utilización como herramienta en el desarrollo de una compra pública estratégica; y la utilidad de la determinación del coste del ciclo de vida para la búsqueda de la oferta que presenta una mejor relación calidad-precio y, en consecuencia, su introducción como criterio para la adjudicación de los contratos públicos.

11 En un trabajo pionero en la construcción del concepto de ciclo de vida del producto como herramienta de marketing (LEVITT, T., "Exploit the Product Life Cycle", Harvard Bussines Review, núm. 43, Noviembre-Diciembre, 1965), al que daría continuidad en obras posteriores (inter alia, "El ciclo de vida del producto: gran oportunidad de marketing", Harvard Deusto Bussines Review, núm. 6, 1981), advierte que, pese al conocimiento por los ejecutivos del ciclo de vida del producto, no se usara de ninguna manera estratégica, y en pocas ocasiones de forma táctica, comparándolo con lo que ocurrió con la visión copernicana del universo 300 años atrás: "mucha gente lo sabía, pero casi nadie parecía utilizarlo de manera adecuada".

12 Vid. CASTElló TALIANI, E./ LIZCANO ÁLVAREZ, J., "Los costes del ciclo de vida del producto: marco conceptual en la nueva contabilidad de gestión", Revista Española de Financiación y Contabilidad, núm. 81, octubre-diciembre, 1994. 
En el ámbito de la contratación pública, la noción de ciclo de vida de un producto o servicio se ha asociado, tradicionalmente, con la introducción de criterios medioambientales en su regulación. No en vano, la inserción en el ordenamiento jurídico español de la noción de ciclo de vida de un producto o servicio se produce inicialmente en el seno de la legislación medioambiental, asignándole diversas funciones y utilidades, pero siempre encaminadas a tomar como referencia el ciclo de vida del producto en la articulación de instrumentos de prevención y protección medioambiental.

Así, la primera referencia de relieve podríamos situarla en el desarrollo en nuestro ordenamiento jurídico del Reglamento 880/1992/CEE, de 23 de marzo, sobre sistema comunitario de etiquetado ecológico, concretado en el R.D. 598/1994, de 8 de abril, y en el que se expone, en relación con la introducción de este sistema, que la finalidad del mismo no es otra que "prevenir, reducir y, en la medida de lo posible, eliminar la contaminación, principalmente en la fuente, para lo que persigue promover la utilización de productos que tengan repercusiones reducidas en el medio ambiente durante todo su ciclo de vida, proporcionando además a los consumidores una mejor información sobre el impacto ecológico de los productos". La repercusión sobre el medio ambiente de un producto no se debe observar sólo en el momento de su utilización, sino en todas las fases de su existencia, lo que incluye por tanto desde su diseño y proyección, hasta su desaparición o eliminación. No se trata tan sólo de que la máquina, por ejemplo, emita la menor cantidad posible de gases mientras se encuentra en uso, o que produzca la menor cantidad de residuos, sino de que su invención y producción, y su retirada y eliminación, también comporten el menor daño posible al medio ambiente.

En esta línea se sitúan referencias posteriores, como la expresada en el art. 1 de la Ley 11/1997, de 24 de abril, de Envases y Residuos de Envases, al definir como objetivo la prevención del impacto sobre el medio ambiente de los envases y la gestión de los residuos de los mismos a lo largo de todo su ciclo de vida; o la previsión contenida en el art. 12 de la Ley 34/2007, de 15 de noviembre, de Calidad del Aire y Protección de la Atmósfera, estableciendo la posibilidad de introducir por vía reglamentaria obligaciones específicas para la fabricación, importación, adquisición intracomunitaria, transporte, distribución, puesta en el mercado o utilización y gestión durante su ciclo de vida de aquellos productos que puedan generar contaminación atmosférica. Posteriormente, como reflejo de un paulatino proceso de utilización de la noción de ciclo de vida de un producto en la legislación medioambiental, cada vez más asentado en la misma, se produce un punto de inflexión con la reiterada referencia a lo largo del articulado de la Ley 22/2011, de 28 de julio, de Residuos y Suelos Contaminados, sirviendo como criterio a tener en cuenta en la definición de la jerarquía de residuos (art. 8), estableciendo la obligación del productor de diseñar productos de manera que a lo largo de todo su ciclo de vida se reduzca su impacto 
ambiental y la generación de residuos, tanto en su fabricación como en su uso posterior (art. 31), y reclamando su aplicación en el proceso de sustitución de las bolsas de un solo uso de plástico no biodegradable (D.A. $2^{\mathrm{a}}$ ).

Con todo, la noción de ciclo de vida de un producto es introducida en nuestro ordenamiento jurídico en materia de contratación pública por medio de la D.A. $1^{\text {a }}$ de la Ley 24/2011, de 1 de agosto, de contratos del sector público en los ámbitos de la defensa y de la seguridad, delimitando que la misma comprende "todas las etapas sucesivas de los productos, a saber, definición del concepto, investigación y desarrollo, desarrollo industrial, producción, reparación, modernización, modificación, mantenimiento, logística, formación, ensayo, baja en servicio y eliminación". Hay que tener en cuenta que la exposición sucesiva de términos asociados a las distintas etapas en la vida del producto, que se dispone en la acotación terminológica a los efectos de aplicación de esta Ley, guarda relación con la posibilidad de ajustar el objeto de los contratos a cada una de ellas (arts. 2 y 7), a lo que se añade la utilización del coste del ciclo de vida como criterio de adjudicación de los contratos (art. 32). Más recientemente, el ciclo de vida es incorporado en la Ley 9/2017, de 8 de noviembre, de Contratos del Sector Público (LCSP), en la que el legislador español ha reproducido casi literalmente la expresión contenida en las Directivas europeas cuya trasposición lleva a cabo, estableciendo en el art. 148.1 LCSP que se entienden comprendidos dentro del ciclo de vida de un producto, obra o servicio, "todas las fases consecutivas o interrelacionadas que se sucedan durante su existencia y, en todo caso: la investigación y el desarrollo que deba llevarse a cabo, la fabricación o producción, la comercialización y las condiciones en que esta tenga lugar, el transporte, la utilización y el mantenimiento, la adquisición de las materias primas necesarias y la generación de recursos; todo ello hasta que se produzca la eliminación, el desmantelamiento o el final de la utilización". Este concepto abarca todo el tiempo que transcurre desde que el producto, obra o servicio es ideado, aun en su más primaria proyección, hasta que desaparece, o como se ha simplificado con acierto, "desde su misma concepción hasta su fin de vida" (FERNÁNDEZ ACEVEDO)13. Lo importante, no obstante, no es tanto la definición temporal, como las circunstancias que deben tenerse en cuenta en cada una de las fases de la creación, vida y desaparición del producto o servicio, y que podríamos descomponer, siguiendo la noción legal, en las siguientes: a) investigación y desarrollo; b) fabricación, incluyendo la adquisición de materias primas y la utilización de recursos; c) comercialización y transporte, d) utilización y mantenimiento; e) eliminación, desmantelamiento y actividades necesarias para su efectiva desaparición.

De la definición del concepto de ciclo de vida de un producto o servicio podemos extraer que permite recopilar toda la información relativa a las diferentes etapas en la vida del mismo, que necesariamente debe estar condicionada por la concreta

13 Cfr. FERNÁNDEZ ACEVEDO, R. (2017: 123). 
utilidad que se pretenda. Como hemos visto, el estudio del ciclo de vida permite su utilización en diferentes vertientes, desde el establecimiento de una planificación comercial encaminada a garantizar el máximo beneficio en el mercado durante el período en que el producto se desenvuelve en el mismo, hasta su incidencia en la medición y control de los costes asociados a las diferentes etapas de la vida del producto en la contabilidad del productor, pasando por su utilidad en la concreción del especial valor ambiental del producto ${ }^{14}$, como criterio definidor de las estrategias de adquisición de productos en el marco de la contratación, tanto pública como privada, desde una perspectiva de sostenibilidad, dirigidas a optimizar el máximo equilibrio entre el desarrollo de la actividad económica y la protección de los intereses diversos de la sociedad.

En esta última funcionalidad del análisis del ciclo de vida de un producto o servicio, desde la óptica de su valor ambiental, la metodología empleada para su estudio es variada, dependiendo de las características que se presenten en cada caso, y de la finalidad que se persiga con su concreción. Con carácter general, la medición del ciclo de vida de un producto o servicio puede realizarse siguiendo las normas en materia de gestión medioambiental UNE-EN ISO 14040 (Principios y Marco de referencia) y UNE-EN ISO 14044 (Requisitos y Directrices), mediante las cuales se lleva a cabo dicho análisis teniendo en cuenta la estructuración del ciclo de vida de un producto o servicio a tenor de tres fases principales: producción, uso y eliminación ${ }^{15}$.

La utilidad que presenta la noción de ciclo de vida de un producto o servicio aplicada a la contratación pública es por tanto múltiple. Su análisis permite extraer una información de sumo valor a la hora de establecer estrategias de adquisición,

14 La conexión entre el ciclo de vida y el valor ambiental de un producto o servicio constituye uno de los elementos nucleares del desarrollo de lo que viene conociéndose como Compra Pública Verde o Contratación Pública Ecológica, en la que se trata de "adquirir productos, servicios y obras con un impacto ambiental reducido durante su ciclo de vida, en comparación con el de otros productos, servicios y obras con la misma función primaria que se adquirirían en su lugar", que es la definición que para la misma se contiene en la Comunicación de la Comisión Europea Contratación Pública para un medio ambiente mejor (COM (2008) 400, pág. 4), y que reproduce literalmente en Plan de Contratación Pública Ecológica aprobado por el Consejo de Ministros de 7 de diciembre de 2018, al que hacíamos referencia anteriormente. De este modo, y en esta dimensión, el análisis del ciclo de vida permite determinar el grado de impacto ambiental de cada producto o servicio, permitiendo concretar las características exigibles a cada uno de ellos para que este sea el menor posible.

15 Sobre la metodología a seguir para el análisis del ciclo de vida de un producto o servicio con carácter general puede consultarse el trabajo de LETÓN GARCíA, P. ("El análisis del ciclo de vida: metodologías y aplicaciones”), en LAZO VITORIA, X. (Dir.), Compra Pública Verde, Atelier, 2018, págs. 347-363. En esta misma obra colectiva se contienen otros estudios de interés que analizan diferentes proyecciones de la utilidad del estudio del ciclo de vida de un producto o servicio asociadas a las políticas europeas de producto, a la economía circular o al sector de la energía (vid. LÓPEZ BLANCO, A.P., "Aplicación del análisis del ciclo de vida a las políticas europeas de producto", págs. 381-390; SENÁN SALINAS, J., "Análisis del ciclo de vida en la economía circular. Aplicaciones en el reciclaje de tecnología de membrana", págs. 391410; DE LA RÚA LOPE, G., "Análisis del ciclo de vida en el sector de la energía”, págs. 411-424). 
atendiendo a diferentes variables que pueden tenerse en cuenta en función de sus características, o de las prioridades en las políticas de contratación desde la perspectiva de su uso estratégico como elemento de desarrollo sostenible. El conocimiento de las particularidades de un producto o servicio en cada una de las fases de su ciclo de vida facilita la selección de los mismos que deben ser objeto de adquisición, pudiendo adoptar decisiones de compra en ejecución de criterios u objetivos previamente fijados en las políticas de contratación, no sólo los ambientales, sino también los sociales o de cualquier otra índole. Por ejemplo, la duración de la vida de un producto no tiene por qué conllevar un impacto medioambiental concreto, pero sí puede ser determinante para la decisión de la idoneidad de su contratación, y del destino de la inversión pública necesaria para ello. En último término, el análisis del ciclo de vida constituye una herramienta imprescindible como base para el cálculo de sus costes, en orden a la utilización de este último instrumento como criterio de adjudicación.

\section{El coste del ciclo de vida de un producto o servicio y su introducción en el régimen de la contratación pública: antecedentes.}

El último avance en la evolución de criterios y principios medioambientales en el ámbito de la contratación pública se refleja en la introducción del coste del ciclo de vida de los productos o servicios como criterio de adjudicación de los contratos. Se trata de una de las novedades que más destacan en la nueva LCSP, que en relación con este instrumento viene a reproducir casi literalmente su tratamiento en la Directiva que traspone en materia de contratación pública ${ }^{16}$. Su inserción en el régimen general de la contratación pública no está exenta de polémica ${ }^{17}$, habida cuenta de su complejidad, cuya virtualidad precisa de un cambio notable en la articulación de los procedimientos de contratación, que necesariamente deberá ir acompañada de una adecuada dotación de recursos materiales y humanos para llevarla a cabo ${ }^{18}$, con el

16 Gomo ha destacado VÁZQUEZ MATILLA (en RAZQUIN LIZÁRRAGA, M.M./ VÁZQUEZ MATILLA, FJ., La adjudicación de los contratos públicos en la nueva Ley de Contratos del Sector Público, Thomson Reuters - Aranzadi, 2017, pág. 217), la LCSP se ha limitado a reproducir el tratamiento de la Directiva 2014/24/UE, de 26 de febrero.

17 Desde una óptica crítica hay quien advierte que este sistema, dada su complejidad, no tendrá prácticamente utilidad en los procedimientos contractuales (Cfr. ESCRIHUELA MORALES, FCO. JAVIER, La Contratación del Sector Público. Especial referencia a los contratos de suministro y servicios, Wolters Kluwer, $5^{\mathrm{a}}$ edición, 2018, pág. 995).

18 En este sentido, coincidimos con SOLA TEYSSIERE cuando señala que uno de los problemas que presenta una implantación de esta herramienta se encuentra en "la ocasional falta de experiencia o preparación del personal de los órganos responsables de gestionarla, debido a la complejidad técnica de la predefinición y cuantificación de los criterios concretos de aplicación de cada caso". A su juicio, supone un cambio de tendencia que requiere la conformación de equipos interdisciplinares y un esfuerzo en la formación del personal especializado (Vid. SOLA TEYSSIERE, J., "El coste del ciclo de vida como criterio de adjudicación del contrato", Contratación Admi- 
objeto de superar los problemas de aplicación y adaptación a la realidad que plantea la introducción de este mecanismo ${ }^{19}$.

La técnica del análisis del coste del ciclo de vida de un producto o servicio, sin embargo, no es tan novedosa como pudiera parecer. Su utilización se remonta a los años setenta del siglo XX, en relación con dos ámbitos diferentes: por un lado, vinculado con la edificación sostenible y el desarrollo de políticas de ahorro energético en el sector de la construcción en el Reino Unido y Estados Unidos ${ }^{20}$; y por otro, como herramienta para la toma de decisiones de inversión en la industria armamentística norteamericana ${ }^{21}$. En el primero de los casos la finalidad de incorporar este instrumento guarda directa relación con los aspectos medioambientales, toda vez que se dirigen a la búsqueda de las soluciones edificatorias más racionales en relación con la utilización de los recursos energéticos y el aprovechamiento de los mismos desde el prisma de su menor impacto ambiental, sin dejar por ello de tener en cuenta las consecuencias en cuanto a la mayor eficiencia económica derivada del menor consumo de energía. En cambio, en el ámbito de la industria militar, el coste del ciclo de vida

nistrativa Práctica, núm. 151, septiembre-octubre, 2017). En la misma línea se expresa PASTOR SÁNCHEZ ("Determinación del coste del ciclo de vida de un contrato público en España para su posible utilización como criterio de adjudicación”, Contratación Administrativa Práctica, núm. 161, mayo-junio, 2019), quien no obstante propone los medios de apoyo con los que puede contar el órgano de contratación para determinar el cálculo del coste del ciclo de vida de un producto, obra o servicio.

19 Como se recoge en el Informe relativo a la Contratación Pública en España - 2017 (Ministerio de Hacienda y Función Pública, abril, 2018, págs. 50 y 74), entre las disposiciones comunitarias que generan importantes problemas de aplicación se encuentra el cálculo del coste del ciclo de vida y la inclusión de aspectos medioambientales vinculados al objeto del contrato, pues " no se está acostumbrado a esto y resulta muy complicado vincularlo al objeto, por ejemplo, en las obras" (sic). En cuanto a la aplicación práctica en materia de contratación pública ecológica, se advierten las siguientes dificultades:

"Si no existen mecanismos/verificaciones oficiales en materia de ciclo de vida, se hace necesario el seguimiento de un producto a lo largo de todo su ciclo de vida para comprobar lo indicado en su oferta por el proveedor en esta materia. Se desconoce si hay metodologías contrastadas en el ámbito de la contratación pública para el seguimiento y análisis de los costes de ciclo de vida de productos y servicios.

Falta de formación y conocimientos de los técnicos para la inclusión de aspectos medioambientales en la redacción de los pliegos de prescripciones técnicas o en las propuestas de valoración de las ofertas. adquirido".

Dificultad en identificar los requisitos ecológicos que realmente impactan en la mejora ambiental del producto o servicio

20 Cfr. GARCIA ERVITI, F./ ARMENGOT PARADINAS, J./ RAMÍREZ PACHEGO, G., "El análisis del coste del ciclo de vida como herramienta para la evaluación económica de la edificación sostenible. Estado de la cuestión", Informes de la Construcción, vol. 67, n 537, 2015.

21 Vid. una detallada exposición de los antecedentes en PASTOR SÁNCHEZ, J., Procedimiento de estimación del coste del ciclo de vida de un sistema de armas en España, Ministerio de Defensa, 2016, pág. 36 (también en "Determinación del coste del ciclo de vida de un contrato público en España para su posible utilización como criterio de adjudicación" (2019: 2). Sobre los antecedentes y evolución de la utilización del coste del ciclo de vida en la industria armamentística norteamericana, vid. NAVARRO GALERA, A./ ORTÚZAR MATURANA, R.I./ ALCARAZ OUILES, F.J., "La viabilidad del coste del ciclo de vida para la evaluación económica de inversiones militares", Revista de Contabilidad, núm. 19, julio-diciembre, 2016, págs. 169-180. 
tiene como principal objetivo lograr la mayor rentabilidad de la inversión en materia de defensa sobre la consideración de los costes asociados a todas las fases de vida del material, dada la relevancia que en este sector adquieren los costes relacionados con el uso y mantenimiento, que pueden llegar a ser muy superiores porcentualmente a los de adquisición ${ }^{22}$.

De este modo, el coste del ciclo de vida se presenta como una herramienta que permite averiguar el alcance de la inversión en un producto o servicio, teniendo en cuenta los costes derivados de cada una de las etapas de su vida, desde su concepción hasta su desaparición. En función de la trascendencia que en cada caso pudiera presentar, ciertamente constituye un mecanismo de suma utilidad para la toma de decisiones de inversión en aras de optimizar la misma en atención a los recursos disponibles. Así, puede valorarse de forma completa o singularizadamente sobre algunas de las etapas de la vida de un producto o servicio, especialmente en aquellas que repercuten en una mayor dimensión en el total de la inversión a realizar. Se trata de un instrumento, pues, de excepcional valía en la búsqueda de la mayor relación coste-eficacia. De ahí que, como ocurría con el concepto de ciclo de vida que veíamos anteriormente, no podamos advertir que estamos necesariamente ante un mecanismo que por sí mismo conduzca exclusivamente a la introducción de criterios medioambientales en la contratación pública, sin perjuicio de que los mismos cobren un especial protagonismo como elementos a considerar en el cálculo de los costes, como veremos más adelante.

En el marco de la contratación pública, en nuestro ordenamiento jurídico se introduce por primera vez el coste del ciclo de vida en 2007, en relación con los criterios de adjudicación de los contratos, estableciéndose en el art. 134.3.h) de la Ley 30/2007, de 30 de octubre, de Contratos del Sector Público, la procedencia de utilizar más de un criterio de adjudicación en aquellos "contratos cuya ejecución pueda tener un impacto significativo en el medio ambiente", para lo que se valorarán "condiciones ambientales mensurables, tales como el menor impacto ambiental, el ahorro y el uso eficiente del agua y la energía $y$ de los materiales, el coste ambiental del ciclo de vida, los procedimientos y métodos de producción ecológicos, la generación y gestión de residuos o el uso de materiales reciclados o reutilizados o de materiales ecológicos". La utilización de la noción coste ambiental del ciclo de vida en este caso es indicativa de la reducción de la técnica a la consideración de los aspectos ambientales en la determinación o fijación de los costes, a los efectos de su valoración por el órgano de contratación. Esta concepción limitada del coste del ciclo de vida a

22 En este sentido, son claramente indicativos de dicha importancia los informes que evalúan que los costes de las inversiones militares, relativos a las fases de utilización y mantenimiento, oscilan según los países entre el 72\% (Estados Unidos, similar en Australia y Nueva Zelanda) y el 80-95\% (Alemania), y cuya referencia puede encontrarse en NAVARRO GALERA, A./ ORTÚZAR MATURANA, R.I./ ALCARAZ QUILES, FJ. (2016: 171). 
su valor medioambiental tiene continuidad en el art. 61.1 in fine de la Ley 31/2007, de 30 de octubre, sobre Procedimientos de Contratación en Sectores Especiales, en el que, sin embargo, desaparece la referencia al coste ambiental del ciclo de vida, pese a lo cual su inclusión en la enumeración de diversos criterios a utilizar en la adjudicación del contrato, todos ellos de carácter ambiental, no altera el alcance limitado del uso de la técnica.

En la misma línea de circunscribir a la dimensión ambiental el cálculo de costes del ciclo de vida se mantiene tiempo después en el art. 35.d) de la Ley 2/2011, de 4 de marzo, de Economía Sostenible ${ }^{23}$, al reiterar, en los mismos términos en que se expresaba la LCSP de 2007, la referencia al coste ambiental del ciclo de vida como criterio de adjudicación en la contratación pública. Sin embargo, con poco margen temporal, y con una diferente visión y amplitud, el legislador español vuelve a utilizar la noción del coste del ciclo de vida en la definición de los criterios de adjudicación en el art. 32 de la Ley 24/2011, de 1 de agosto, de contratos del sector público en los ámbitos de defensa y de la seguridad. En este caso, a diferencia de los anteriores, se establece la posibilidad de que puedan utilizarse varios criterios para la adjudicación de los contratos, cuando este no sea único y referido al precio más bajo, enumerando una serie de ellos a título indicativo, sin que los mismos se refieran exclusivamente a criterios medioambientales, como sí establecía con claridad el legislador de 2007, y abarcando cuestiones como: la calidad, el precio, el valor técnico, el carácter funcional, las características medioambientales, el coste de utilización, los costes a lo largo del ciclo de vida, la rentabilidad, el servicio posventa y la asistencia técnica, la fecha de entrega y el plazo de entrega o de ejecución, la seguridad del abastecimiento, la interoperabilidad y las características operativas. De esta relación de criterios llama la atención que se expongan, como si fueran diferentes, el coste de utilización y el coste a lo largo del ciclo de vida. Si entendemos que este último debe incluir los costes derivados de la utilización y mantenimiento, carecía de sentido dicho distingo, salvo que con su separación el legislador pretendiera mantener la visión reducida a la dimensión ambiental de los costes que había venido utilizando anteriormente.

23 Como señala GOMEZ RUIZ, M. (2015: 310), la perspectiva del análisis de los costes a lo largo del ciclo de vida de los productos fue introducida por la Directiva 2009/33/CE, traspuesta a nuestro ordenamiento por la Ley 2/2011, de 4 de marzo, de Economía Sostenible, obligando a utilizar los costes de consumo de energía durante la vida útil, las emisiones de $\mathrm{CO} 2$ y las emisiones contaminantes como criterios de adjudicación en la compra de vehículos destinados a los servicios de transporte público. 


\section{EL GOSTE DEL CICLO DE VIDA DE LOS PRODUCTOS Y SER- VICIOS GOMO CRITERIO DE ADJUDICACIÓN.}

\section{Los criterios de adjudicación en la LGSP de 2017: la sustitución de la "oferta económicamente más ventajosa" por la "mejor relación calidad-precio".}

Uno de los aspectos en los que se presenta un cambio notable en la reciente reforma del régimen de la contratación pública es en relación con los criterios de adjudicación de los contratos. Desaparece en la nueva LCSP la referencia a la oferta económicamente más ventajosa, pese a que la Directiva 2014/24/UE sigue utilizando esta noción (art. 67), y a que para la determinación de la misma ya el legislador anterior preveía la introducción de numerosos criterios: calidad, precio, fórmula utilizable para revisar las retribuciones ligadas a la utilización de la obra o la prestación del servicio, plazo de ejecución o entrega de la prestación, coste de utilización, características medioambientales o vinculadas con la satisfacción de exigencias sociales, rentabilidad, valor técnico, características estéticas o funcionales, disponibilidad y coste de repuestos, mantenimiento, asistencia técnica, servicio postventa u otros semejantes (art. 150.1 del Real Decreto Legislativo 3/2011, de 14 de noviembre, Texto Refundido de la Ley de Contratos del Sector Público-TRLCSP-).

Siguiendo la indicación de la propia Directiva 2014/24/UE (considerando $89)^{24}$, con mayor rigor por tanto que en el propio articulado de la misma, que como vemos mantiene la noción de "oferta económicamente más ventajosa", el legislador español ha decidido prescindir de esta última, sustituyendo este criterio por el de "mejor relación calidad-precio", en línea con lo que viene demandándose en el marco del desarrollo de las políticas europeas en materia de regulación de la contratación pública ${ }^{25}$.

$24 \mathrm{Al}$ abordar los criterios de adjudicación, el Cdo. 89 de la Directiva propone este cambio de terminología en los siguientes términos: "Para evitar confusión con los criterios de adjudicación conocidos como la "oferta económicamente más ventajosa" en las Directivas 2007/7/CE y 2004/18/CE, procede utilizar una terminología distinta para abarcar dicho concepto: la "mejor relación calidad-precio". Por consiguiente, se debe interpretar con arreglo a la jurisprudencia relativa a dichas Directivas, salvo cuando exista una solución material y claramente diferente en la presente Directiva".

25 Las posiciones en las instituciones europeas vienen sucediéndose en esta línea, como la Comunicación de la Comisión Europea, de 3 de octubre de 2017 (COM (2017) 572 final), para conseguir que la contratación pública funcione en Europa y para Europa, en la que se aboga por la introducción de criterios innovadores, ecológicos y sociales, y se apuesta por la búsqueda de la mejor calidad-precio ( $c f r$ VÁZQUEZ MATILLA (2017: 183)). Más reciente, y en el mismo sentido, el Dictamen del Comité Económico y Social Europeo sobre "La evolución estratégica de la política industrial hacia el año 2030, a fin de reforzar la base industrial competitiva y diversificada en Europa y concentrarse en los resultados a largo plazo en las cadenas de valor mundiales" (DOCE C62, de 15 de febrero de 2019, pág. 22), sostiene que "la contratación pública estratégica constituye una palanca importante de la política industrial. Habrí que aprovechar plenamente su potencial 
El cambio de paradigma no puede entenderse sino desde la óptica de introducir un elemento crucial en el desarrollo de una compra pública estratégica. No se trata de buscar el menor desembolso, o el mayor ingreso, según el tipo de contrato de que se trate, sino de alcanzar el objetivo de implementar un uso estratégico de la contratación pública como instrumento de desarrollo sostenible ${ }^{26}$. Sobre esta base, la adjudicación de los contratos públicos debe realizarse utilizando una pluralidad de criterios, con el objetivo de conseguir la mejor relación calidad-precio (art. 145.1 LCSP). Para llegar a satisfacer esta finalidad, esta relación calidad-precio puede obtenerse utilizando a su vez dos tipos de criterios: económicos y cualitativos. Entre los primeros debe atenderse a la mejor relación coste-eficacia, tomando como referencia bien el precio, bien el cálculo del coste del ciclo de vida, identificándose este último instrumento desde la perspectiva de la rentabilidad (at. 145.1 párr. $2^{\circ}$ en relación con el apartado 2. párr. $2^{\circ}$ LCSP) ${ }^{27}$.

Estos criterios económicos deberán incluirse en la determinación de los elementos a tener en cuenta para la adjudicación de los contratos en todo caso, sin perjuicio de la integración de criterios cualitativos, cuya exposición se contiene en el art. 145.2 LCSP, a título enunciativo, abarcando:

$1^{\circ}$.- La calidad, incluido el valor técnico, las características estéticas y funcionales, la accesibilidad, el diseño universal o diseño para todas las personas usuarias, las características sociales, medioambientales e innovadoras, y la comercialización y sus condiciones. En lo que respecta a los aspectos sociales y medioambientales, el propio art. 145 LCSP contiene también a título indicativo algunos elementos que pueden tomarse como referencia ${ }^{28}$.

integrando unos criterios innovadores, ecológicos y sociales en las licitaciones públicas, en lugar de limitarse a buscar el precio más bajo".

26 En este sentido, DELGADO FERNÁNDEZ ("El cálculo del coste del ciclo de vida en la contratación administrativa", Gabilex, núm. 7, septiembre, 2016, pág. 122-124) destaca la intención de las instituciones europeas de fomentar el uso estratégico de la contratación pública. A su juicio, en este uso estratégico es donde debe integrarse el cálculo del coste del ciclo de vida, sobre todo en los siguientes aspectos:

a) Implantación de estrategias propias y consecución de los objetivos incluidos en las mismas: la aplicación correcta y eficiente del cálculo del coste del ciclo de vida requiere del establecimiento previo de líneas estratégicas (el poder adjudicador debe determinar su inclusión en una medida pertinente, o si es la totalidad o parte de los costes, y las fases del ciclo de la vida que se utilizarán)

b) Orientación hacia la calidad de la contratación pública: el fomento del cálculo del coste del ciclo de vida permite una atención especial a la relación calidad-precio

27 Como advierte SARASIBAR IRIARTE ("Cláusulas ambientales en la contratación pública: referencia al ciclo de vida como criterio de adjudicación”, en RAZQUIN LIZARRAGA, M.M. (Dir.) (2017: 141), la Directiva 2014/24/UE asocia el concepto coste del ciclo de vida como un indicador de la eficacia o rentabilidad, es decir, una relación entre los ingresos que produciría y el coste de la inversión.

28 Como se recoge en el art. 145.2.1 ${ }^{\circ}$ LCSP, en el caso de los aspectos medioambientales se podrán tener en cuenta cuestiones como la reducción del nivel de emisión de gases de efecto invernadero, el em- 
$2^{\circ}$.- La organización, cualificación y experiencia del personal adscrito al contrato que vaya a ejecutar el mismo, siempre y cuando la calidad de dicho personal pueda afectar de manera significativa a su mejor ejecución.

$3^{\circ}$.- El servicio posventa y la asistencia técnica y condiciones de entrega tales como la fecha en que esta última debe producirse, el proceso de entrega, el plazo de entrega o ejecución y los compromisos relativos a recambios y seguridad del suministro.

La adjudicación del contrato público deberá atender, por tanto, a una pluralidad de criterios dirigidos a conseguir que la inversión a realizar garantiza la mayor optimización de los recursos desde la perspectiva de ponderar el esfuerzo financiero necesario con el nivel de calidad de los resultados alcanzados, dentro del esquema de una utilización estratégica de la contratación pública que convierte a esta en un instrumento clave en el desarrollo de una economía sostenible. El objetivo es apartarse de la concepción de que el contrato público debe ser referenciado sobre el precio más bajo de adquisición, en el entendimiento que ello no contribuye a una mejor gestión de los recursos públicos, si sólo se tiene en cuenta el valor de adquisición, y no otros elementos como los fondos que son necesarios destinar durante la ejecución del contrato, incluidos los relativos a la eliminación o desaparición del producto, obra o servicio, o el impacto de la ejecución del contrato en otros ámbitos, como la repercusión medioambiental o social, que indirectamente provocan un coste para las arcas públicas que debe ser asumido desde el desarrollo de políticas sociales o medioambientales dirigidas a paliar los efectos provocados por el mismo.

En la anterior regulación, el art. 150 del TRLCSP de 2011 exponía toda una serie de criterios que podían tomarse como referencia para la determinación de la oferta económicamente más ventajosa, mezclando aquellos de carácter económico, como el precio, el coste de utilización o la rentabilidad, con otros de carácter cualitativo, como las características estéticas o funcionales, la asistencia técnica o el servicio posventa. Pese al reconocimiento de esta pluralidad de criterios, el esquema dispuesto establecía que, de optarse por la utilización de uno solo, este debía ser el precio más bajo.

pleo de medidas de ahorro y eficiencia energética procedentes de energías renovables durante la ejecución del contrato, y el mantenimiento o mejora de los recursos naturales que pudieran quedar afectados por la ejecución del contrato. Por lo que respecta a las características sociales, estas podrán referirse al fomento de la integración social de personas con discapacidad, personas desfavorecidas o miembros de grupos vulnerables entre las personas asignadas a la ejecución del contrato; la inserción sociolaboral de personas con discapacidad o en situación o riesgo de exclusión social; subcontratación con Centros Especiales de Empleo o Empresas de Inserción; planes de igualdad de género que se apliquen en la ejecución del contrato; conciliación de la vida laboral, personal y familiar; mejora de las condiciones laborales y salariales; estabilidad en el empleo; contratación de un mayor número de personas para la ejecución del contrato; formación y protección de la salud y la seguridad en el trabajo; aplicación de criterios éticos y de responsabilidad social; suministro o utilización de productos basados en un comercio equitativo durante la ejecución del contrato. 
Con el sistema adoptado por la nueva LCSP de 2017, se dota de una mayor coherencia en la construcción de los criterios de adjudicación de los contratos públicos. Partiendo de la necesariedad de contar al menos con criterios de carácter económico, se separan los mismos de aquellos que se caracterizan por valorar los aspectos cualitativos de la ejecución del contrato, evitando con ello la confusión entre ambos. Del mismo modo, se simplifican los criterios económicos, reduciéndose a su estimación bien sobre el precio, bien sobre los costes de ejecución del contrato, medidos estos últimos desde el prisma del mayor coste-eficacia, en términos de rentabilidad.

En la construcción de los criterios de adjudicación, por otro lado, no se establece ninguna regla que pondere el adecuado equilibrio entre los criterios económicos y los cualitativos, lo que hubiera sido deseable para evitar controversias derivadas del amplio margen que el legislador parece admitir. La única limitación que al respecto se dispone viene fijada en el art. 145.4.párr. $2^{\circ}$ LCSP por la obligación de que los aspectos cualitativos representen al menos el 51\% de la puntuación asignable en los contratos de servicios relacionados en el Anexo IV LCSP, así como aquellos que tienen por objeto prestaciones de carácter intelectual. En cualquier caso, el art. 146.3 LCSP establece que salvo que se utilice el precio como criterio único, deberá establecerse la ponderación relativa a cada uno de los criterios de valoración, que podrá expresarse fijando una banda de valores con una amplitud máxima adecuada, todo ello debidamente expresados en el pliego de cláusulas administrativas particulares o en el documento descriptivo. Cuando esta ponderación no sea posible por razones objetivas debidamente justificadas, los criterios se enumerarán por orden decreciente de importancia. Del mismo modo, cuando el procedimiento de adjudicación se articule en varias fases, se indicará en cuales de ellas se aplica cada criterio, estableciendo un umbral mínimo del 50 por ciento de la puntuación en el conjunto de los criterios cualitativos para continuar el proceso selectivo.

\section{El cálculo del coste del ciclo de vida como criterio de adjudicación alternativo al precio.}

Para la concreción de la oferta que debe ser seleccionada se prevé como veíamos la utilización de una pluralidad de criterios de adjudicación. Con el objetivo de fomentar la aplicación de más de un criterio, el art. 145.3 LCSP establece un listado de supuestos en los que obligatoriamente procederá su uso, sin que se establezca un quantum mínimo o máximo de criterios a seleccionar ${ }^{29}$, lo que conduce a extender este régimen a una multiplicidad de situaciones en la práctica. Sin embargo, esta opción

29 Deberá utilizarse más de un criterio de adjudicación cuando se trate de los siguientes contratos (art. 145.3 LCSP):

a) Aquellos cuyos proyectos o presupuestos no hayan podido ser establecidos previamente y deban ser presentados por los candidatos o licitadores. 
por la que apuesta el legislador no es obstáculo para que prevea a su vez la utilización de un solo criterio (art. 146.1 LCSP) ${ }^{30}$. En este caso, si en el art. 150 TRLCSP de 2011 el criterio único había de ser el precio más bajo, la nueva norma establece que lo determinante sea o bien el precio o bien un criterio basado en la rentabilidad, como el coste del ciclo de vida. De ello pueden extraerse dos conclusiones: en primer lugar, que el legislador presenta una doble alternativa (precio o rentabilidad), de modo que el poder adjudicador deberá optar entre si toma como referencia el precio o el coste del ciclo de vida ${ }^{31}$; y, en segundo lugar, que la introducción del concepto de coste de ciclo de vida tiene carácter indicativo, de modo que lo determinante en este caso es que la alternativa al precio la constituya cualquier criterio basado en la rentabilidad, siendo el coste del ciclo de vida una propuesta, pero sin que sea el único método exclusivo (en principio, nada impide que se pueda utilizar cualquier otro criterio

b) Cuando el órgano de contratación considere que la definición de la prestación es susceptible de ser mejorada por otras soluciones técnicas o por reducciones en su plazo de ejecución.

c) Aquellos para cuya ejecución facilite el órgano, organismo o entidad contratante materiales o medios auxiliares cuya buena utilización exija garantías especiales por parte de los contratistas.

d) Aquellos que requieran el empleo de tecnología especialmente avanzada o cuya ejecución sea particularmente compleja.

e) Contratos de concesión de obras y concesión de servicios.

f) Contratos de suministros, salvo que los productos a adquirir estén perfectamente definidos y no sea posible variar los plazos de entrega ni introducir modificaciones de ninguna clase en el contrato, siendo por consiguiente el precio el único factor determinante de la adjudicación.

g) Contratos de servicios, salvo que las prestaciones estén perfectamente definidas técnicamente y no sea posible variar los plazos de entrega ni introducir modificaciones de ninguna clase en el contrato, siendo por consiguiente el precio el único factor determinante de la adjudicación.

En los contratos de servicios que tengan por objeto prestaciones de carácter intelectual, como los servicios de ingeniería y arquitectura, y en los contratos de prestación de servicios sociales si fomentan la integración social de personas desfavorecidas o miembros de grupos vulnerables entre las personas asignadas a la ejecución del contrato, promueven el empleo de personas con dificultades particulares de inserción en el mercado laboral o cuando se trate de los contratos de servicios sociales, sanitarios o educativos a que se refiere la Disposición adicional cuadragésima octava, o de servicios intensivos en mano de obra, el precio no podrá ser el único factor determinante de la adjudicación. Igualmente, en el caso de los contratos de servicios de seguridad privada deberá aplicarse más de un criterio de adjudicación.

h) Contratos cuya ejecución pueda tener un impacto significativo en el medio ambiente, en cuya adjudicación se valorarán condiciones ambientales mensurables, tales como el menor impacto ambiental, el ahorro y el uso eficiente del agua y la energía y de los materiales, el coste ambiental del ciclo de vida, los procedimientos y métodos de producción ecológicos, la generación y gestión de residuos o el uso de materiales reciclados o reutilizados o de materiales ecológicos.

30 Como advierte SOLA TEYSSIERE, J. (2017:.4), el legislador no sólo no lo prohíbe, sino que incluso permite la utilización de un único criterio.

31 Así lo entienden también FERNÁNDEZ ACEVEDO Y VALCÁRCEL FERNÁNDEZ ("Análisis de los criterios de adjudicación de los contratos públicos en el marco de la cuarta generación de Directivas del sector", en FERNÁNDEZ ACEVEDO, R./ VALCÁRCEL FERNÁNDEZ, P. (Dir.), La Contratación Pública a debate: presente y futuro, Thomson - Reuters - Civitas, 2014; pág. 212), para quienes se trata de elegir entre dos posibilidades, el precio o el coste, de forma alternativa, o una u otra. 
que permita hallar la mayor rentabilidad). En este punto, una apuesta firme por la eficacia de esta herramienta en el marco de la contratación pública debería pasar por una determinación más clara en el fomento de utilización de la misma, que habría de comenzar por su reconocimiento como el criterio a seguir para la determinación de la mayor rentabilidad, pues de lo contrario se corre el riesgo de que los problemas de claridad y definición que plantean su uso lleven a que el mismo tenga un carácter residual en el ámbito que nos ocupa, por las dificultades prácticas que acarrea.

Para la determinación del coste del ciclo de vida, el art. 148.2 LCSP reproduce literalmente lo dispuesto en este sentido en el art. 68.1 de la Directiva 2014/24/ UE, en el que se establece que el mismo podrá componerse atendiendo a los costes incurridos a lo largo del ciclo de vida del producto, obra o servicio, que podrán ser de doble origen:

a) Costes directos: asumidos por el órgano de contratación o por otros usuarios, y que comprenden los relativos a la adquisición, la utilización (para lo que introduce a título ejemplificativo los costes de consumo de energía y otros recursos), el mantenimiento y el final de vida (en este caso, al igual que antes, indicando como ejemplo los costes de recogida y reciclado).

b) Costes indirectos: imputados a externalidades medioambientales vinculadas al producto, obra o servicio durante su ciclo de vida. En este punto se exige como condición que su valor monetario pueda determinarse y verificarse. A título indicativo, la norma europea y, en consecuencia, la española, se refieren al coste de las emisiones de gases de efecto invernadero y de otras emisiones contaminantes, así como otros costes de mitigación del cambio climático, lo que no impide incluir otros conceptos similares que puedan ser debidamente valorizados.

Esta exposición de conceptos que pueden integrarse en el cálculo del coste del ciclo de vida no implica que, de utilizarse este criterio de adjudicación, todos deban integrarse en la determinación del cálculo final. En este sentido parece clara la flexibilidad que introduce la norma europea y, por consiguiente, la española, al expresar que el cálculo incluirá "la totalidad o una parte de los costes" descritos (art. 68.1 Directiva 2014/24/UE y art. 148.2 LCSP). Realmente, el cálculo del coste del ciclo de vida es una herramienta propia de la contratación pública estratégica, que va más allá de la dimensión medioambiental que va asociada a la misma ${ }^{32}$. Su inserción en el marco de la contratación pública permite analizar cuáles son las decisiones más acertadas para el logro de los fines estratégicos que la nueva visión de la regulación

32 Como ha señalado BUZARCO SAMPER ("Los criterios de adjudicación", en ALONSO TIMÓN, A.J. (Coord.), Contratación Pública, Dykinson, 2018, pág. 154), aunque el coste del ciclo de vida se ha relacionado comúnmente con los costes ambientales, el manejo que la LCSP hace del concepto es, sin duda, más amplio. 
de la contratación pública viene planteando, ofreciendo la información precisa para fijar adecuadamente el ajuste entre la inversión pública y los costes derivados de la misma $^{33}$. De ahí que lo coherente sea permitir que en cada caso se fije qué costes son los que deben tenerse más o menos en cuenta para buscar la mayor rentabilidad en las ofertas presentadas. Dependiendo de las características de la prestación, tendrá más peso algunas de las etapas del ciclo de vida de un producto, obra o servicio, que otras, lo que podrá tenerse en cuenta para lograr esa pretendida ecuación del mejor coste-eficacia.

El coste del ciclo de vida se presenta, pues, como un instrumento propio y característico de la contratación pública estratégica ${ }^{34}$, sin que pueda ceñirse su análisis a la perspectiva medioambiental que en el mismo concurre, ni tampoco deba desdeñarse la importancia de esta. Con todo, no hay que dejar de observar que con la introducción del coste del ciclo de vida como criterio económico en la adjudicación de los contratos estamos ampliando la relevancia de los aspectos medioambientales en el marco de la contratación pública ${ }^{35}$, que ahora encuentran su operatividad en los dos tipos de criterios de adjudicación, económicos y cualitativos, lo que contribuye a incrementar su virtualidad ${ }^{36}$.

El problema principal que se plantea en la efectiva incorporación de esta herramienta en el ámbito de la contratación pública se centra en la dificultad de con-

33 A juicio de SOLA TEYSSIERE el objetivo básico de coste del ciclo de vida no es otro que facilitar la decisión de adquisición de un objeto de entre varias ofertas del mismo, considerando "no solo su precio de adquisición, sino todos los flujos financieros - costes y posibles ingresos- que dicho objeto va a generar en un horizonte temporal determinado" (2017: 4). En el mismo sentido, FERNÁNDEZ ACEVEDO destaca también la utilidad de cuantificar la totalidad de los gastos (directos o indirectos; fijos o variables) que presenta un bien o una prestación, a lo largo de toda su vida útil, sin que ello conduzca necesariamente a la adopción por el poder adjudicador de un mayor desembolso (2017: 123), y SARASIBAR IRIARTE advierte que con ello puede conocerse cuánta inversión se va a requerir en el tiempo, teniendo en cuenta cada una de las fases del producto o servicio (2017: 141).

34 Interesante en este punto es la perspectiva que apunta NUÑEZ LOZANO (2016: 116), al analizar cómo este instrumento puede combinarse con los objetivos y prioridades que se plantean en la compra pública innovadora, todo ello dentro el marco de un uso estratégico de la contratación pública.

35 En esta línea, BLANCO LÓPEZ mantiene que supone un cambio de planteamiento radical, al tenerse en cuenta la variable ambiental no sólo exclusivamente en la ponderación de la calidad, sino también en la determinación del coste económico ("Los criterios de adjudicación en la contratación pública estratégica", en GIMENO FELIU, J.Ma (Dir.), Estudio sistemático de la Ley de Contratos del Sector Público, Thomson Reuters - Aranzadi, 2018, pág. 1291).

36 Como ha expuesto SARASIBAR IRIARTE (2017: 142), "la ventaja del análisis del CCV es la detección pormenorizada del momento en que un producto resulta más o menos ecológico. $\mathcal{Y}$ con ese análisis, se identifican las oportunidades para mejorar los impactos ambientales considerando el ciclo de vida completo del producto, se fijan prioridades para el diseño ecológico del producto, se comparan distintas opciones de diseño de productos y se estudia la obtención de ayudas y subvenciones como consecuencia de la reducción de impacto ambiental'. 
cretar su cálculo ${ }^{37}$, ante la ausencia de una metodología clara para el mismo ${ }^{38}$. A este respecto, el art. 148.2 in fine LCSP, siguiendo lo dispuesto por la Directiva, establece que en el caso de que una norma europea hiciera obligatorio un método común para calcular los costes del ciclo de vida, este habría de aplicarse imperativamente en su evaluación ${ }^{39}$. Hasta la fecha, esta metodología sólo ha sido establecida en la contratación pública en el ámbito de la Directiva 2009/33/CE, de 23 de abril de 2009, relativa a la promoción de vehículos de transporte por carretera limpios y energéticamente eficientes ${ }^{40}$, definiendo el método de cálculo de los costes de utilización durante la vida útil del consumo de energía, de las emisiones de CO2 y de las emisiones contaminantes enumeradas en el anexo de la Directiva, que estén ligados a la explotación de los vehículos objeto de compra, que deberán cuantificarse económicamente y calcularse conforme a las reglas indicadas en el art. 6 de la Directiva. Sin perjuicio de que el método propuesto por esta Directiva posea algún margen de mejora ${ }^{41}$, lo cierto es que facilita el desarrollo del cálculo de los costes sobre la base de establecimiento de unos criterios concretos y objetivos.

La determinación y cálculo de los costes del ciclo de vida no es tarea sencilla, entre otros motivos por la inexistencia de un modelo claro de evaluación, de ahí que se sostenga con acierto lo deseable que resultaría el establecimiento de una metodología armonizada en el ámbito europeo, como señalábamos anteriormente. Con todo, hemos de tener en cuenta que estamos ante una técnica de cálculo de costes, donde la dificultad no se encuentra sólo en la concreta aplicación, para la que habremos de introducir herramientas propias de la contabilidad ${ }^{42}$, sino en la previa fijación de

37 Como destaca VÁZQUEZ MATILLA (2017: 220).

38 Vid. BUZARCO SAMPER, M. (2018): 154; RAZQUIN LIZARRAGA, M.M., "Mecanismos para la inclusión de cláusulas ambientales en los contratos públicos", en RAZQUIN LIZARRAGA, M.M. (Dir.), (2017): 173-174; FERNÁNDEZ ACEVEDO, R., (2017: 123).

39 De forma crítica, SOLA TEYSSIERE advierte, en relación con la inexistencia de esta metodología común, que no parece que las autoridades comunitarias ni la mayoría de los Estados tengan un decidido empeño en su desarrollo (2017: 6).

40 Esta Directiva ha sido recientemente reformada por medio de la Directiva 2019/1161/UE, de 20 de junio de 2019, cuya entrada en vigor se dispone a partir del 2 de agosto de 2019 y que obliga a adaptar las legislaciones nacionales a sus determinaciones a más tardar el 2 de agosto de 2021, aunque las modificaciones introducidas no afectan al establecimiento de la metodología a seguir para el cálculo de los costes de utilización.

41 En este sentido SOLA TEYSSIERE entiende que el modelo "podría ser mejorado, incluyendo en la valoración costes relevantes como los consumos de fluidos, mantenimientos y otros factores ahora ausentes" (2007: 6)

42 Un primer acercamiento a la comprensión de la metodología a seguir para el cálculo del coste del ciclo de vida puede consultarse en la GUÍA COMPRA PÚBLICA VERDE Y ANÁLISIS DE COSTES DEL CICLO DE VIDA, editada por IHobe y el Departamento de Medio Ambiente y Política Territorial del Gobierno Vasco, en septiembre de 2016 (págs. 7-10).

Con mayor detenimiento, pueden verse los trabajos de GÓMEZ GUZMÁN (La determinación del precio de los contratos públicos con base en el coste, Wolters Kluwer, 2018; "La ecuación del "coste del ciclo 
los elementos y aspectos de las distintas etapas del ciclo de vida de los productos y servicios, sobre los que estimamos conveniente llevar a cabo la operación de traducir monetariamente su valor, en orden a seleccionar la mejor oferta desde la perspectiva coste-eficacia, como impone el nuevo régimen de la contratación pública. El obstáculo no se encuentra tanto en el concreto cálculo del coste de una fase específica, o de una parte de ella, del ciclo de vida de un producto o servicio, y de los elementos a considerar en la misma, sino en determinar qué tipo de costes (directos e indirectos) y en atención a qué conceptos, van a tomarse en cuenta para el cálculo, toda vez que, como veíamos, el esquema adoptado permite seleccionar todos o parte de los costes del ciclo de vida, lo que en la práctica deja un abanico de posibilidades que podría ser demasiado abierto para que este instrumento opere con ciertos márgenes de seguridad.

\section{Los requisitos y condiciones para la introducción del cálculo del coste del ciclo de vida como criterio de adjudicación.}

La materialización de la introducción del criterio del coste del ciclo de vida en la adjudicación de un contrato público requiere adicionalmente del cumplimiento de una serie de requisitos y condiciones, unos exigibles con carácter general a todos los criterios de adjudicación, y otros específicamente relativos a dicho instrumento (arts. 145.5-6 y 148.3 LCSP). De entrada, deben establecerse en el pliego de cláusulas administrativas particulares o en el documento descriptivo, precisando la ponderación relativa a cada uno de los criterios de valoración, y figurar en el anuncio que sirva de convocatoria de licitación, debiendo tener en cuenta además las siguientes cuestiones:

1. En primer término, es necesario que los elementos que hayan sido incluidos en el cálculo del costo del ciclo de vida estén vinculados con el objeto del contrato ${ }^{43}$,

de vida" (CCV). Procedimientos y metodología de su cálculo, y del criterio de valoración y adjudicación", Contratación Administrativa Práctica, no 154, marzo-abril, 2018).

También pueden citarse destacadamente aquellos trabajos que parten de la operatividad del instrumento del cálculo del coste del ciclo de vida en dos sectores en los que, como hemos visto, se sitúan en el origen de la incorporación de este instrumento en el ámbito de la contratación pública, como el sector de la construcción (GARCIA ERVITI, F./ ARMENGOT PARADINAS, J./ RAMÍREZ PACHECO, G. (2015)) y el de la defensa (en el que sobresale la excelente tesis doctoral de PASTOR SÁNCHEZ, J., Procedimiento de estimación del coste del ciclo de vida de un sistema de armas en España (2016) así como su reciente trabajo "Determinación del coste del ciclo de vida de un contrato público en España para su posible utilización como criterio de adjudicación" (2019); también en el ámbito de la defensa NAVARRO GALERA, A./ ORTÚZAR MATURANA, R.I./ ALCARAZ QUILES, FJ. (2016))

43 A estos efectos, VÁZQUEZ MATILLA advierte que debe extremarse el celo con la exigencia de requerimientos ambientales que no tienen relación con el objeto del contrato, lo cual ha sido cuestionado por los Tribunales de recurso especial, como recoge la propia Exposición de Motivos de la LCSP (2017: 217). En este sentido, los tribunales vienen declarando como improcedentes aquellos criterios que no tienen una vinculación directa con el objeto del contrato, lo que se presenta sobre todo en relación con la introducción de criterios sociales (vid., inter alia, las Sentencias del Tribunal Superior de Justicia de Madrid, de 23 de 
considerándose que esto ocurre cuando se refiera o integre las prestaciones que deban realizarse en virtud del contrato, en cualquiera de sus aspectos y en cualquier etapa de su ciclo de vida, incluidos los factores que intervienen en los procesos de producción, prestación o comercialización, o cualquier otro en las etapas del ciclo de vida, conforme a lo establecido en el art. 145.5 y 6 LCSP.

2. Deben ser formulados de manera objetiva ${ }^{44}$, con pleno respeto a los principios de igualdad, no discriminación, transparencia y proporcionalidad, sin conferir al órgano de contratación una libertad de decisión ilimitada

3. Deben garantizar la posibilidad de que las ofertas sean evaluadas en condiciones de competencia efectivas e ir acompañados de especificaciones que permitan comprobar la información facilitada por los licitadores con el fin de evaluar la medida en que las ofertas cumplen los criterios de adjudicación ${ }^{45}$. En caso de duda, debe comprobarse la exactitud de la información y las pruebas facilitadas por los licitadores.

4. Cuando los costes se evalúen tomando como referencia el cálculo del coste del ciclo de vida, en los pliegos deberán indicarse los datos que tienen que facilitar los licitadores para la determinación de dicho cálculo, así como el método que se utilizará para el mismo, sobre la base de los datos facilitados. En el caso de los costes relativos a las externalidades medioambientales, el método establecido deberá cumplir con las siguientes condiciones:

a) Estar basado en criterios verificables objetivamente y no discriminatorios; en particular, si no se ha establecido para una aplicación repetida o continuada, no deberá favorecer o perjudicar indebidamente a empresas determinadas.

b) Ser accesible a todas las partes interesadas.

c) La información necesaria debe poder ser facilitada con un esfuerzo razonable por parte de las empresas, incluidas aquellas procedentes de Estados signatarios del Acuerdo sobre Contratación Pública de la Organización Mundial de Comercio o de otros Estados signatarios de algún otro Acuerdo Internacional que vincule a España o a la Unión Europea.

febrero de 2018 y de 14 de marzo de 2019, y del Tribunal Superior de Justicia de Andalucía (Sevilla), de 5 de septiembre de 2017 y 5 de diciembre de 2017).

44 El carácter objetivo es determinante para cumplir con los principios que se exigen (vid. SARASIBAR IRIARTE, M., (2017: 142).

45 Compartimos plenamente la opinión de FERNÁNDEZ ACEVEDO, al destacar que para cumplir con estos principios y evitar distorsiones en la competencia es imprescindible el establecimiento de métodos armonizados y simplificados de evaluación económica en el marco de la UE, y no metodologías ad hoc que producirían un efecto no deseado (2017: 123). 


\section{REFLEXIÓN FINAL.}

El proceso de transformación del esquema regulador en el ámbito de la contratación pública, de un tiempo a esta parte, viene marcado por un cambio de paradigma que supone una nueva concepción de esta como un instrumento estratégico en el desarrollo de políticas públicas, superando la visión de la compra pública como un ejercicio de mera gestión del gasto público. En este contexto, la operatividad de las nociones de ciclo de vida de un producto o servicio y su coste, adquiere especial importancia como mecanismo que va a contribuir a alcanzar el objetivo de la mejor relación calidad-precio en la adquisición de bienes y servicios en el ámbito sujeto a las normas en materia de contratación pública.

De ambas nociones debe destacarse, por encima de todo, su especial valor como instrumento estratégico, más allá de su consideración como elementos propios de la introducción de cláusulas o criterios medioambientales en el sistema de contratación pública. Del análisis del ciclo de vida de un producto o servicio se puede extraer información relativa al impacto ambiental de todas las fases de su ciclo de vida, pero también permite conocer otros caracteres que pueden incidir en otras variables a tener en cuenta en la planificación estratégica de la compra pública (como el número de empleos que genera su producción, la cualificación de estos, o la duración de su utilización, por citar sólo algunos ejemplos). No en vano, la aparición de este concepto de ciclo de vida de un producto o servicio, en su génesis, está íntimamente ligada con su condición de instrumento estratégico.

Lo mismo ocurre con la introducción del coste del ciclo de vida como criterio de adjudicación de los contratos, sustituyendo al precio. No parece que la dificultad del uso de esta herramienta se encuentre tanto en el efectivo cálculo del coste, para lo que habrá que remitirse a las técnicas propias de la contabilidad de costes, como en la decisión de los concretos elementos que deben integrarse en dicho cálculo. La generalización de su utilización requerirá, además de la adopción de metodologías uniformes en función de grupos de productos o servicios, y de una cierta labor pedagógica en materia de formación de equipos profesionalizados y especializados, así como algunas modificaciones en sede normativa que manifiesten una decidida apuesta por la eficacia de esta herramienta y su utilidad para lograr la mayor rentabilidad en la adjudicación de la compra pública. Al igual que con el ciclo de vida de un producto o servicio, su coste no sólo puede advertirse como un elemento característico de la compra pública ecológica o medioambiental, sino que, más allá, adquiere una especial dimensión como arma estratégica en la toma de decisiones para la planificación de la contratación pública. No obstante, ello no es obstáculo para considerar que la construcción de esta figura en el plano normativo permite observar que la incorporación de cláusulas medioambientales en la contratación pública ya no 
sólo se articula mediante el reconocimiento de aspectos cualitativos, sino también de carácter cuantitativo, lo que sin duda amplía la atención a los valores ambientales. 


\section{BIBLIOGRAFÍA.}

- BLANCO LÓPEZ, F., "Los criterios de adjudicación en la contratación pública estratégica", en GIMENO FELIU, J.M (Dir.), Estudio sistemático de la Ley de Contratos del Sector Público, Thomson Reuters - Aranzadi, 2018.

- BUZARCO SAMPER, M., "Los criterios de adjudicación", en ALONSO TIMÓN, A.J. (Coord.), Contratación Pública, Dykinson, 2018.

- CASTELLÓ TALIANI, E./ LIZCANO ÁLVAREZ,J., "Los costes del ciclo de vida del producto: marco conceptual en la nueva contabilidad de gestión", Revista Española de Financiación y Contabilidad, núm. 81, octubre-diciembre, 1994.

- COMISIÓN EUROPEA, Adquisiciones ecológicas. Manual sobre contratación ecológica pública, $3^{\text {a }}$ edición, Oficina de Publicaciones de la Unión Europea, 2016.

- DELGADO FERNÁNDEZ, Ma R., "El cálculo del coste del ciclo de vida en la contratación administrativa", Gabilex, núm. 7, septiembre, 2016.

- ESCRIHUELA MORALES, FCO. JAVIER, La Contratación del Sector Público. Especial referencia a los contratos de suministro y servicios, Wolters Kluwer, $5^{\text {a }}$ edición, 2018.

- FERNÁNDEZ ACEVEDO, R., "Los retos ambientales de las nuevas directivas. La contratación pública como estrategia”, en RAZQUIN LIZARRAGA, M.M. (Dir.), Nueva contratación pública: mercado y medio ambiente, Thomson Reuters - Aranzadi/ Universidad Pública de Navarra, 2017.

- FERNÁNDEZ AGEVEDO, R./ VALGÁRGEL FERNÁNDEZ, P. (Dir.), La Contratación Pública a debate: presente y futuro, Thomson Reuters - Civitas, 2014.

- FERNÁNDEZ SCAGLIUSI, M ${ }^{\mathrm{a}}$ A., "Un nuevo procedimiento de adjudicación de contratos públicos: la asociación para la innovación", en GIMENO FELIÚ, J.M. (Dir.), Las nuevas Directivas de Contratación Pública, Thomson Reuters - Aranzadi, 2015.

- GARCIA ERVITI, F./ ARMENGOT PARADINAS, J./ RAMÍREZ PACHECO, G., "El análisis del coste del ciclo de vida como herramienta para la evaluación económica de la edificación sostenible. Estado de la cuestión", Informes de la Construcción, vol. 67, núm. 537, 2015.

- GARCÍA JIMÉNEZ, A., Las conexiones entre contratación pública e innovación, Tecnos, 2018.

- GIMENO FELIÚ,J.M., "La nueva regulación de la contratación pública en España desde la óptica de la incorporación de las exigencias europeas: hacia un mo- 
delo estratégico, eficiente y transparente”, en GIMENO FELIÚ, J.M. (Dir.), Estudio sistemático de la Ley de Contratos del Sector Público, Thomson Reuters - Aranzadi, 2018.

- GIMENO FELIÚ, J.M., "El nuevo paquete legislativo comunitario de contratación pública: principales novedades. La orientación estratégica de la contratación pública”, en RODRÍGUEZ-GAMPOS GONZÁLEZ, S. (Goord.), Las nuevas directivas de contratos públicos y su transposición, Marcial Pons, 2016.

- GIMENO FELIÚ, J.M., El nuevo paquete legislativo comunitario sobre contratación pública. De la burocracia a la estrategia (El contrato público como herramienta de liderazgo institucional de los poderes públicos), Thomson Reuters - Aranzadi, 2014.

- GÓMEZ GUZMÁN, J.C., La determinación del precio de los contratos públicos con base en el coste, El Consultor - Wolters Kluwer, 2018.

- GÓMEZ GUZMÁN, J.C., "La ecuación del "coste del ciclo de vida” (CGV). Procedimientos y metodología de su cálculo, y del criterio de valoración y adjudicación”, Contratación Administrativa Práctica, núm. 154, marzo-abril, 2018.

- GÓMEZ RUIZ, M., Aspectos sociales y medioambientales en la contratación pública, Tesis Doctoral, Universidad de Cádiz, noviembre de 2015.

- HERNANDO RYDINGS, M., "El procedimiento de asociación para la innovación”, en GIMENO FELIÚ, J.M., Estudio sistemático de la Ley de Contratos del Sector Público, Thomson Reuters - Aranzadi, 2018

- LAZO VITORIA, X. (Dir.), Compra Pública Verde, Atelier, 2018.

- LETÓN GARCÍA, P., "El análisis del ciclo de vida: metodologías y aplicaciones”, en LAZO VITORIA, X. (Dir.), Compra Pública Verde, Atelier, 2018.

- LEVITT, T., "Exploit the Product Life Cycle", Harvard Bussines Review, Noviembre, 1965.

- LEVITT, T., "El ciclo de vida del producto: gran oportunidad de marketing", Harvard Deusto Bussines Review, núm. 6, 1981.

- NAVARRO GALERA, A./ ORTÚZAR MATURANA, R.I./ ALCARAZ QUILES, FJ., "La viabilidad del coste del ciclo de vida para la evaluación económica de inversiones militares", Revista de Contabilidad, núm. 19, julio-diciembre, 2016.

- NUÑEZ LOZANO, G., "La contratación pública innovadora: compras comerciales y compras precomerciales", en HERNÁNDEZ GONZÁLEZ, F.L. (Coord.), El impacto de la crisis en la contratación pública: España, Italia, Francia, Thomson Reuters - Aranzadi, 2016. 
- PASTOR SÁNGHEZ, J., "Determinación del coste del ciclo de vida de un contrato público en España para su posible utilización como criterio de adjudicación”, Contratación Administrativa Práctica, núm. 161, mayo-junio, 2019.

- PASTOR SÁNCHEZ, J., Procedimiento de estimación del coste del ciclo de vida de un sistema de armas en España, Ministerio de Defensa, 2016.

- PERnÁS GARCíA, J.J. (Dir.), Contratación Pública Estratégica, Aranzadi, 2013.

- RAZQUIN LIZARRAGA, M.M., "Mecanismos para la inclusión de cláusulas ambientales en los contratos públicos", en RAZQUIN LIZARRAGA, M.M. (Dir.), Nueva contratación pública: mercado y medio ambiente, Thomson Reuters - Aranzadi/ Universidad Pública de Navarra, 2017.

- RAZQUIN LIZARRAGA, M.M./ VÁZQUEZ MATILLA, F.J., La adjudicación de los contratos públicos en la nueva Ley de Contratos del Sector Público, Thomson Reuters - Aranzadi, 2017.

- RODRÍGUEZ BEAS, M., "La compra pública innovadora en la nueva Directiva de Contratación Pública”, en GIMENO FELIÚ, J.M. (Dir.), Las nuevas Directivas de Contratación Pública, Thomson Reuters - Aranzadi, 2015.

- SARASIBAR IRIARTE, M., "Cláusulas ambientales en la contratación pública: referencia al ciclo de vida como criterio de adjudicación”, en RAZQUIN LIZARRAGA, M.M. (Dir.), Nueva contratación pública: mercado y medio ambiente, Thomson Reuters - Aranzadi/ Universidad Pública de Navarra, 2017.

- SOLA TEYSSIERE, J., "El coste del ciclo de vida como criterio de adjudicación del contrato", Contratación Administrativa Práctica, núm. 151, septiembre-octubre, 2017. 